\title{
BJPsych Open editorial transition: opportunity, challenge and vision
}

\author{
Kenneth R. Kaufman
}

\section{Summary}

BJPsych Open enters its fourth year with a transition in leadership and a new Editor-in-Chief (EIC). This editorial summarises the Journal's metrics through its first 36 months, provides insights into the Journal's history and growth, and shares the aspirations of the new EIC for BJPsych Open.

\section{Declaration of interest}

K.R.K. is Editor-in-Chief of BJPsych Open; he took no part in the peer-review of this work.

\section{Copyright and usage}

(C) The Royal College of Psychiatrists 2018. This is an Open Access article, distributed under the terms of the Creative commons Attribution-NonCommercial-NoDerivatives licence (http://creativecommons.org/licenses/by-nc-nd/4.0/), which permits noncommercial re-use, distribution, and reproduction in any medium, provided the original work is unaltered and is properly cited. The written permission of Cambridge University Press must be obtained for commercial re-use or in order to create a derivative work.
Kenneth R. Kaufman (pictured) is Professor of Psychiatry, Neurology and Anesthesiology at Rutgers Robert Wood Johnson Medical School (New Brunswick) and Editor-in-Chief of BJPsych Open.
It seems only yesterday that the Royal College of Psychiatrists announced the addition of BJPsych Open to its publication portfolio. ${ }^{1}$ Initially, BJPsych Open was published quarterly, which rapidly increased to six issues yearly. With this editorial, we have now been in press for 30 months with a total of 14 issues. An earlier assessment of our productivity and breadth under the helm of the founding BJPsych Open Editor-in-Chief (EIC) Professor Kamaldeep Bhui, with Deputy Editors Kenneth Kaufman and Gin Malhi, was performed when BJPsych Open had been in press for 12 months; ${ }^{2}$ these metrics have now been reassessed for the full 36 months under this leadership team. This editorial revisits them, as the Journal embarks on its fourth year of life with my transition to the role of EIC, and provides insights into the Journal's history and progression, and my future aspirations for its maturation and growth.

To date, 2918 authors from 43 countries have submitted 489 papers. The acceptance rate has averaged 32.5\%, resulting in 159 accepted papers representing 953 authors from 30 countries and six continents. The total number of authors and the international representation continue to grow. Further, the number of reviewers has increased from a total of 318 reviewers from 39 countries at the first assessment, to 1114 reviewers from 55 countries at the current assessment. Whereas BJPsych Open was initially conceived as a cascade journal from the British Journal of Psychiatry, BJPsych Open continues to receive an ever-increasing and significant number of independent submissions, which speaks to its growing reputation. Further, BJPsych Open is now indexed in PubMed Central and the Emerging Science Citation Index.

The publication partnership between the Royal College of Psychiatrists and Cambridge University Press (RCPsych-CUP) should facilitate increased quality submissions with a greater international presence, further indexing and a future impact factor. Although I envision achieving a target impact factor of 2-3 within the next 5-7 years, this should not be considered a surrogate definition for the quality of BJPsych Open; rather, the impact factor should be high enough to attract superior submissions but not so high as to preclude publication of meaningful clinical research, including case reports. Justifiably or not, the impact factor has a degree of importance in our world of academic bibliometrics, which may influence promotion, tenure and grant funding; however, as EIC, I recognise that excellent papers, whether important clinical observations, translational research or those affecting policy, may not be cited initially, but may later be cited for many years to come. As such, the impact factor will be driven by the quality of accepted submissions, not a predetermined target number. The emphasis of BJPsych Open will always be the publication of meritorious articles that influence all aspects of mental health and associated fields - from translational research to clinical research; from stigma and quality of life to caregiver burden and coping strategies for severe mental illness; and from treatment outcomes to healthcare economics, service delivery and national policy. Further, as an open access journal, BJPsych Open can be flexible in responding both to volume and type of articles with publication within 28 days of acceptance.

The key strengths leading to the continuing success of BJPsych Open are our submitting authors, our dedicated reviewers, and a tireless editorial board that focuses on rigorous peer review with requisite sound methodology and high academic standards. During this transition, it is worth noting recent additions to the board - Dr Marco Mula (Senior Lecturer, St George's University of London), Dr Regi Alexander (Research Lead Consultant, Leicestershire Partnership NHS Trust, and Honorary Senior Lecturer, University of Leicester), Dr Sara Evans-Lacko (Associate Professor, London School of Economics and Political Science, and Senior Lecturer, Institute of Psychiatry, Psychology and Neuroscience, King's College London), Professor Allan Young (Chair of Mood Disorders at King's College London), Professor Nadia Micali (Head of Division, Child and Adolescent Psychiatry, University of Geneva, Switzerland, and Senior Lecturer, Institute of Child Health, University College London), Dr Renee C. Fox (Annenberg Professor Emerita of the Social Sciences, University of Pennsylvania, Philadelphia, USA), Professor Danuta Wasserman (University Professor in Psychiatry and Suicidology, Karolinska Institute, Stockholm, Sweden) and Dr Eva Petkova (Director of Biostatistics; Associate Professor, Departments of Child and Adolescent Psychiatry and Population Health, NYU School of Medicine, New York, USA). I envisage that the editorial board will continue to grow as it has done thus far to cover the different psychiatric specialties and subspecialties with international representation. 
Further, the BJPsych Open editorial board will remain supported by the British Journal of Psychiatry board, thus ensuring the maximal standards expected from the BJPsych brand and the Royal College of Psychiatrists.

BJPsych Open currently publishes editorials, research articles, reviews and short reports, including unusual case studies. In the future, BJPsych Open will also include commentaries, correspondence and special communications, including periodic ethics, sociology and humanism papers.

The challenge posed to any incoming EIC is to both maintain and surpass the standards established by the outgoing EIC. Although BJPsych Open has grown since its inception, the opportunity exists to raise this bar higher, increase the international authorship/reviewer base, and attract and/or commission editorials, articles, reviews and special papers addressing new trends in mental health research, service delivery, policy and ethics. To attain such will require input from the entire editorial board, from submitting authors and from the College, but also from our readers, whose correspondence and comments are key reminders that journals do not exist in a vacuum but publish meaningful articles for an audience.

The vision for BJPsych Open is the maintenance of an academically rigorous general psychiatric journal with a renaissance flavour: ${ }^{3}$ (a) in which no high-quality paper that is methodologically sound, original and with clinical relevance is rejected; (b) in which all specialties, subspecialties and associated fields have space; (c) that continues to publish editorials, research articles and short papers, including case reports, with the addition of commentaries, correspondence and special communications; (d) that has a strong editorial board with an international base; (e) that publishes at least one thematic issue annually; (f) that will remain an egalitarian journal, economically accessible for all authors who desire to publish; (g) that continues to grow in submissions, authors, acceptances and reputation; and (h) that is both author friendly and highly readable. To ensure that all this is possible, with the new RCPsych-CUP partnership, BJPsych Open will publish commissioned papers and editorials, utilise country-specific article publishing charge waivers, and permit discretionary waivers with the assistance of a newly created Academic Freedom Fund.

The entire BJPsych Open team thanks the authors, reviewers and readers for their continuing support and looks forward to further growth with the RCPsych-CUP partnership.

Kenneth R. Kaufman, MD, FRCPsych, DLFAPA, FAES, Departments of Psychiatry Neurology, and Anesthesiology, Rutgers Robert Wood Johnson Medical School, 125 Paterson Street, Suite \#2200, New Brunswick, New Jersey 08901, USA. Email: kaufmakr@ rwjms. rutgers.edu

First received 5 Jan 2018, final revision 21 Jan 2018, accepted 30 Jan 2018

\section{Acknowledgments}

I thank Kam for affording me this opportunity as EIC, Gin for his ongoing support of my role, and both for comments on earlier drafts of this editorial.

\section{References}

1 Bhui K, Malhi GS, Kaufman KR. Open sesame: a new generation journal. BJPsych Open 2015; 1(1): e1-2.

2 Kaufman KR, Malhi GS, Baxter A, Bhui K. In an open publishing house not so far, far away.... BJPsych Open 2016; 2(4): e12-3.

3 Kaufman KR. The Renaissance scholar in academic medicine: the road less traveled. Aust N Z J Psychiatry 2017; 51(12): 1250-1. 